\title{
Deep Knowledge: A Strategy For University Budgetary Cuts
}

Douglas B. Reynolds, The University of Alaska Fairbanks, USA

\begin{abstract}
During and after the Financial Crisis of 2008, many institutions of higher learning have had revenue and budgetary reductions, forcing them to make severe university budget cuts and university reductions in force. Often the university cuts are preceded by a process of evaluation of academic programs where institutions determine what they stand for and value. One option, when forced to downsize, is to use a business model, such as Sullivan (2004) explains, where high-value, low-cost programs are kept and low-value, high-cost programs are cut. However, a business model of education does not reflect the true social value of education or the importance of arts, sciences and humanities, where students learn how to struggle with, write about and understand the world. John Henry Cardinal Newman's (1852) treatise, The Idea of a University, suggests an alternative strategy of cost cutting that has to do with deep knowledge, i.e. keep the oldest programs in existence on a given university. Using the deep knowledge concept, a university will cut young (junior programs) first and retain old (senior) programs until the very last, rather than deciding cuts based on a business model. The deep knowledge concept emphasizes a Socratic ideal where professors and students wrestle over concepts, such as the meaning of "beauty."
\end{abstract}

Keywords: University Budget Cut; Idea of a University; Business Model; University Program Reductions

\section{INTRODUCTION}

reat universities have a tripartite mission of teaching, research, and service. Ideally, when it comes to teaching, a university is not a "place" of learning but an environment where learning can occur and where professors and students struggle together to understand knowledge. The struggle for knowledge is not unlike the Socratic ideal where professors and students wrestle over concepts, such as the meaning of "beauty," where the struggle to understand "beauty" is not unlike the struggle to start a business or create new laws or invent a machine. Such intellectual struggles encompass many of struggles of life with which a student eventually will deal. Therefore, when it comes to defining what a university program should include for its teaching mission, it should be understood that the main purpose of a university is first and foremost to induce students to think through problems, challenges, and principles rather than to have students regurgitate readymade answers.

Furthermore, a university conducts research. Again, ideally, a university should not be a place of research, but an environment where professors are allowed time and money to explore new realms of knowledge, to research and understand new ideas, and to share that knowledge with their students and the community. Professors should conduct experiments, read information, and write new equations to expand society's knowledge base. Much of this new knowledge would not necessarily cause an increase in the Gross Domestic Product (GDP), the output of goods and services that the economy produces in a given year, but rather it would increase society's well-being in ways that society cannot evaluate monetarily. The appropriate metric for research would include articles, books, grants, observations or experiments that can be used to increase the knowledge base.

Finally, a university conducts service. A university should create an environment where faculty can help students, help university governance, help professional organizations, help government, and help industry to make them all run better. Service can also be conducted to help the wider community to interface with all arts and sciences. Moreover, the faculty at a given university should be allowed to give regional specific teaching, regional specific research, and regional specific service, in all lines of expertise, which can add much value to the local community. 
Nevertheless, as great as all this can be and as important as it is, there are limits to the resources that society can provide to a university and as such the business side of a university must be taken into account. Every institution, from research facilities to governments, and to households are beholden to a budget. When severe budget cuts are needed due to financial crises, then all institutions are forced to cut back and reduce their scope of work. Such budget cuts, then, require that society question the purpose of institutions, such as universities. In such an instance, a university needs to find out what it stands for and what its most important departments and research agendas are to make the most efficient cuts. These ideas go back to John Henry Cardinal Newman's (1852) treatise, The Idea of a University.

\section{THE IDEA OF A UNIVERSITY}

If you were on a deserted island, with no way to leave, you would be hard pressed to be able to create a modern economy on that island complete with computers, i-phones, and plastic shelving. Indeed, no one person can recreate all that the economy has to offer such as types of food, types of materials for construction, and types of machinery. Such a complex economy requires complex expertise, people who are specialists in so narrow a field and yet so broad a knowledge base within that field, that no one else has the faintest clue about what they do. Such specific tasks take years to perfect and require a life-time of commitment to achieve excellence.

Therefore what students learn from school is not specific knowledge on how to carry out a specific technical task that helps to build our economy; rather we learn general knowledge, general culture, and general academic skills to help in the pursuit of specific business and social welfare goals. After all, no one person coming out of a university is capable of knowing all specific tasks that occur within any given field. Indeed, even when you know quite a bit about a very narrow field of endeavor you are still required to continue reading, studying and upgrading your knowledge base about that field to keep up with its changing scope. Therefore, since no one college or university could have all the expertise in the world that can cover every last minutia of detail for every field of knowledge, then it is impossible for a university to be able to prepare every student to a perfect level of mastery for a given career. Universities cannot hope to impart specific competence, but rather they engender general knowledge and understanding, upon which the student continues his development with work experience. Schooling can never replace work experience.

But if we step back a bit, we can see that we must also learn general education used to live our lives with all of the society. As Newman says: “(a) university should put before it, as its great object, to make its students 'gentlemen,' ... and not simply to protect the interests and advance the dominion of science." However, when universities emphasize very specific lines of scientific or business endeavors, then this, "...is the sort of institution, which primarily contemplates science itself, and not students..."

Thus, the true nature of a university is not to have extremely focused specializations for students, but rather there should be general arts, general sciences, general engineering, and general business and economics that teach students how to carry out critical thinking skills, writing skills and study skills. Moreover, we need students to learn a broad range of related subjects that help students make connections between various fields of knowledge and industry. Where would Henry Ford's assembly line be without finance? Where would Rockefeller's Oil Empire be without chemists? Where would medicine be without generals of war trying to save their soldiers' lives? There is a lot of interconnectedness in business, in technology, and in life, but it gets missed in the enthusiasm for specialization. Moreover, students need to become gentlemen and ladies which means to become cultured, to be knowledgeable about the world, its politics, its culture and its interactions and to be able to express ideas coherently, or as John Henry says:

When the intellect has once been properly trained and formed to have a connected view or grasp of things, it will display its powers with more or less effect according to its particular quality and capacity in the individual. In the case of most men, it makes itself felt in the good sense, sobriety of thought, reasonableness, candor, self-command, and steadiness of view, which characterize it. In some, it will have developed habits of business, power of influencing others, and sagacity. In others, it will elicit the talent of philosophical speculation, and lead the mind forward to eminence in this or that intellectual department. In all, it will be a faculty of entering with comparative ease into any subject of thought, and of taking up with aptitude any science or profession. 
The ideal of general intellectual development, then, should be considered when a university has to endure cuts for financial reasons. However, instead of this ideal, society seems to believe that a university should pursue a business model.

\section{THE BUSINESS MODEL OF A UNIVERSITY}

Consider a typical university process of budget cutting. Using what might be called "the business model," Mitchell and Coles (2004) suggest that universities should compare costs and benefits of different programs with each other, and the University should keep low-cost, high-benefit programs, while the University reduces high-cost, low-benefit programs. The administration can then pick and choose where to cut, where to maximize the value of the University as a whole and where to reallocate resources efficiently. However, there is no known metric for determining the value of a program. Any given line of research, service or teaching cannot be scientifically valued following the principles of a business model. Carlsona and Fleisherb (2007) and Armstrong (2003) explain this reduces the efficacy of a college education, but they give no solution for making cuts.

Additionally, within the business model, a university also has to deal with faculty seniority, which is often a key union agreement, or even a non-union or tacit agreement, between the faculty and the administration at many universities. Universities often use the seniority system within the business model when cuts are made, whereby the University does not replace older professors, or older lecturers, who retire. Alternatively, if the University does replace older professorial or lecturer positions, it is with part-time, low-paid instructors. Thus, in general, the University replaces high-paid, research positions with low-paid, non-research oriented instructors. The depth and breadth of what is being taught and researched are of little concern compared to monetary consideration. Another strategy used is to simply lay-off professors, lecturers, or instructor positions based on seniority, and, therefore, the University cuts the lowest seniority positions first.

The problem with the seniority strategy of cutting is that there can be valuable programs with many retiring faculty that don't get replaced, leaving a vacuum in that program with no high-ranking professors left to teach, to do research or to do service within that program. Also, cuts can be done by cutting or laying-off many low-seniority faculty in a valuable program. The low-seniority faculty may be in a valuable program and have lots of students and lots of research money, but the administration cuts them. Administration then turns around and keeps senior faculty, which may be in a low-valued program with low numbers of students and no grant or research money. What you would rather do is cut low-priority programs so that the administration can staff all remaining high-priority programs at a full contingent level. However, cutting by priority begs the question of how exactly the administration can determine a value of any given program to determine what is the definition of low and high-priority.

Recall, the business model for a university, after labor seniority issues are resolved, is predicated on cutting the least valuable programs or entities first, as defined in cost/benefit business terms, and then cutting the most valuable programs or entities later, also defined in cost/benefit business terms. Usually, that leaves the judgment of a program's benefit to a simple numbers game of counting up the number of students or the number of student credit hours or the number of students who graduate from a given program as the criteria of value. Administration then cuts programs with low use of student services, with low use of instructor services and with few class sections, while administration keeps programs with high-usage and many class sections.

One of the problems with using the student-choice criteria for determining value is that students have little experience from which to judge what is truly valuable. Students have an incentive to gravitate toward programs that give its graduates the highest potential monetary value, regarding future earnings but also programs that incur the least amount of work. Also, students shy away from new challenging classes and choose only what they like. Plus there is a fashion element involved. A new program on web-based social media will tend to garner much more interest than an undergraduate degree in mathematics, and yet society may, in fact, need people with more math skills than social media skills. Therefore, it is not a particularly sound strategy to cut programs based solely on the whims of students. Likewise, the local community surrounding a university can be pulled in a multiple of directions of fashion that influence what programs at the University are valuable and what programs at the University are worth cutting. The latest study or the latest trend as to what is valuable to a community, such as a health program or an energy program, can sway the community to have a certain program when such programs may only be what is desired now. 
One additional business model strategy that universities often undertake is to have across-the-board pay-cuts. The idea of across the board cuts sounds reasonable, since after all, if the economy at large is in crisis, then university faculty should likewise sacrifice. However, care should be taken that pay cuts do not unduly harm faculty. When faculty undergo to research a new field or write a book, or conduct experiments with long-run implications, they do not have a lot of time to take care of additional responsibilities for managing money that can become more onerous. Faculty can be forced to spend more time managing their finances when they must endure pay cuts or worse yet; they may be forced to take on additional courses or to teach more sections of courses or to conduct more service tasks to augment their pay. Such sacrifices can severely constrain research, teaching and service efforts by the faculty, and thus, severely undermine the purpose of a university. Either you commit to stand for something or you don't. [p. 12, 98]

\section{AN EXAMPLE OF THE SOCRATIC DIALECTIC METHOD}

Imagine Socrates is in charge of cutting the University. He begins his inquiry by having a dialog with his students. Socrates asks the students, "What knowledge is the most important knowledge to know?"

The student may answer that being able to fix a horse-drawn cart is the most important knowledge to know because if you cannot fix a horse-drawn cart, you cannot get food from the farm to your house and you will die. Socrates might retort that if you know how to find a person who can fix a horse-drawn cart, and if you can manage to have them available during emergencies, then that would be even more important knowledge. So the conclusion is that knowing how to fix a horse-drawn cart is not as important as knowing how to find someone to fix a horse-drawn cart, which then allows you to specialize in another profession or need.

Assume the student agrees. However, the student is still fixated on the horse-drawn cart as being important. So the student might say that knowing technical knowledge about horse-drawn carts is the most important knowledge since if I know how to invent a new type of horse-drawn cart, say a better or a cheaper horse-drawn cart, which can get more food to market, then that technical knowledge is the most important knowledge. So, Socrates puts forth that if you are about to die, then is it truly the case that the most important piece of knowledge is knowing that you have helped all these people due to you being able to make a better horse-drawn cart? Would not life's struggles, life's meaning, or life's beauty not be paramount to you? Is that all you would think about, just that you had the skills to build a better horse-drawn cart?

Then the student might say well yes, having knowledge of life's struggles, life's meaning or life's beauty is important and perhaps even more important than having the technical knowledge to build a better horse-drawn cart. Then Socrates says, "so the technical knowledge is more important than the skill to fix a horse-drawn cart, but less important than the knowledge of life's meaning. So, technical knowledge is important; it is unimportant; what then constitutes important knowledge?" Just so, university administrators can argue that some specific programs are important and unimportant at the same time, but then there is no true justification for what constitutes a valuable program and what cuts are appropriate for a business model. Probably no definitive conclusion would ever be reached by Socrates or his students. No student, nor administrator, nor community leader, nor faculty member, could ever argue effectively or prove that one line of discipline at the University is more important than another.

As an example, many argue that computer skills are vital to today's business. Alternatively, there are many people who went to university and studied business, engineering or mathematics with little or no computer science classes or little or no computer science background, since it was so new a few decades ago, and yet they have entire careers based on using computer code and programming computers. Such computer work is possible because academic skills allow a person to figure out and learn computer science skills, and learn how to be able to work with computers. It is not the specific skills one learns at college, but rather the general skills that one learns at college which makes the difference. Basic skills such as logic, writing, science and mathematics are the most helpful skills when learning how to program a computer whether or not one has learned the specific practice of computer programming.

There are also many people who went to university and had no training on spreadsheet usage, such as on excel, no training on word processing programs, such as on publisher, or no training on speech presentation software, such as on power point, and yet they use spreadsheets, use word processing software, and use speech presentation software 
every day. Such accomplishments are made possible because of having a university degree where one becomes proficient at writing, logic and science. The reason it is possible to learn how to use these technologies is because a university is where you learn how to organize your answers, how to write reports, and how to conduct basic sciences all of which makes it easy to learn how to use computers as a tool. You learn how to find answers on your own. A university is not actually a skills center, it is a learning center where you learn to struggle through challenges of learning and where you learn to learn.

After all, many business leaders, scientists and commentators suggest that to have new advancement in technology and business, you have to think "outside of the box." At the same time all the computer programmers, business managers and engineers are trained ever more intensely to be "in the box." Therefore, maybe if computer programmers and others could write eloquently, could reason sophisticatedly and could understand a broad spectrum of arts and sciences, they would think outside of the box and innovate more freely.

Indeed, I have noticed in the classroom that the more students have and use modern information technology, the worse they write, the worse their presentations are and the worse their mathematical skills have become. They are unable to organize themselves since they rely so heavily on their technology to organize things for them. They cannot come to appropriate conclusions. Their critical thinking skills are very weak. In essence, we use technology to open a caterpillars cocoon with the butterfly within it, only to find that the butterfly cannot fly. The butterfly cannot fly because, by opening the cocoon for the butterfly too early, the butterfly does not get the appropriate strength and conditioning it needs as it struggles to get out on its own, and struggles to push open the cocoon. So by not struggling, the butterfly wings do not strengthen and develop naturally and are then not strong enough to fly.

Therefore, the main thing one learns at university is not specific technical skills; rather one learns how to think critically, like Socrates and his students. As long as you have a background in mathematics and science, a background in writing and discourse, and a background in research and study, then you can figure out anything else you need to know, such as computer programming, language skills, biological relationships, leadership skills or business accounting. You can understand what you need in business by reading, by taking supplemental classes or just by figuring it out on your own. Thus, there is no rational reason to cut or keep any specific university program. Clearly, though, college programs that make students struggle to learn and which sharpen their minds are very important programs compared to a college program that simply give away answers.

Therefore, one idea to consider using for when an economic crisis of cutbacks confronts a university is the concept of deep knowledge.

\section{THE DEEP KNOWLEDGE MODEL}

Civilization, culture, and business have evolved due to an ever greater knowledge base for humankind as Jackson (2014) shows. Each new discovery and each new line of reasoning by society are dependent on previous discoveries and previous lines of reasoning, building on top of one another into an ever greater volume of arts and science literature. Nevertheless, the deepest knowledge upon which to base the current modern knowledge remains, and those early building blocks can be called deep knowledge. Deep knowledge means the knowledge that humans discovered earliest in time: the deeper the knowledge, the earlier its initial discovery.

Besides deep knowledge referring to early intellectual discoveries, it can also refer to programs, majors or departments that exist at a university. Early struggles within a subject matter induce the creation of new subjects, new programs, and new departments at a university. Such struggle is rather like Marx's and Hegel's ideas on dialectics where a thesis and an antithesis collide and struggle together to create a synthesis. Yet, within each synthesis is a new thesis from which a new antithesis emerges and from which a new round of struggle occurs. The idea of deep knowledge is almost the reverse. As knowledge builds in one line of reasoning, there occurs an internal struggle that creates two new lines of reasoning. The initial line of reasoning encapsulated in a university program or department keeps on going, but a new line of reasoning encapsulated in a new program or a new department, splits off from the old line of reasoning and becomes an independent tree limb of knowledge and an independent university department and an independent university program. Indeed, it is often a specific struggle in a given field of study and how that struggle created new knowledge and a new understanding that is the point in time when a new university program gets started. Since all 
knowledge and all subjects created are derivative of earlier knowledge and earlier subjects then they all matter. Since it was previous fields of study that induced new knowledge and new fields of study in the first place, then those previous fields should be prioritized. So, instead of creating a hierarchy of programs based on the business model of a university, university administration should prioritize programs based on the concept of a seniority. Therefore, senior programs are assigned the highest preference to remain and junior, or recent, programs are cut. Such a method of cuts can be called the "deep knowledge" strategy to university cuts.

Based on The Idea of a University, it is the struggle for knowledge by students that is the most important aspect of the University experience rather than the specific knowledge that students learn. Therefore, if a university cuts programs and majors in reverse seniority, there would be no loss in the University experience. For example, many universities cut first the last people hired and then cut last the longest tenured faculty, i.e. "last hired, first fired." An alternative method that a university can adopt would follow this same hierarchical process only for program cuts, i.e. cut entire programs and majors in a similar sequence. That is, instead of cutting faculty by the rule of "last hired, first fired," cut entire programs by the rule of the last program that the University starts becomes the first program it cuts, i.e. "last inaugurated, first terminated." This method of cutting can be called the "Deep Knowledge" criteria for making cuts. Since all knowledge is derivative of earlier knowledge, then keeping the earlier senior programs at a given university can still allow students to consider the newer subjects during a student's career at a university.

\section{Deep Knowledge and Seniority}

Here is how cuts would work. A university that needs to make cuts to reduce its costs will look at all the majors, all the programs, and all the departments that it has instituted within itself as spelled out in its university bulletin or catalog. The University then looks at previous year's catalogs, one after the other, starting with the most recent. Any new programs, new majors or new departments that the University starts between the latest two consecutive catalogs are cut. Faculty in those programs that are cut will be allowed to move to other programs if they can teach in the other programs and it they are accredited in them. Senior faculty especially will be allowed to find a place to teach within the realm of their expertise in another department of their choosing. In this way, the administration can move professors into older programs that the deleted program faculty can choose, and in which that faculty will have to do one research product related to that new field within five years or in general follow the other department's procedures for research, teaching and service.

Programs that are important to a university's overall mission, or accreditation due to applicable law, such as diversity related programs, can be allowed to stay even if they are young programs; however, such programs must have a majority of the University's faculty champion those programs by a vote. Then, if more cuts are needed, the University will go back to older catalogs to find more junior programs to cut. A university or college will keep cutting programs, majors, and departments in reverse order to each one's start date, until the University is on a sound economic footing.

One might suggest that this idea of cutting junior programs is not a good idea at all. If you cut, say, a computer science program before, say, a mechanical engineering program, then you ruin progress. The mechanical engineering program may be an older program, which would mean the University will keep it, yet the University will cut the new, hightech computer science program that looks to be so important for the future of economic growth and of business. So, the University keeps the curmudgeonly old, useless mechanical engineering program that is not what society needs, but cuts the computer science program that is what society needs. When you think in terms of deep knowledge, mechanical engineering is often the senior program that presages computer science. Mechanical engineering has an older literature, a deeper knowledge base, and so it is more fundamental to society's historic technical advancement, and, therefore, many universities will cut mechanical engineering last and cut computer science first if it uses the criteria of deep knowledge.

Many a computer programmer or a computer company would protest such a cut, but computer companies can hire mechanical engineers, mathematicians or even philosophy majors, who are willing to be trained in computer science, to take care of each firm's needs. Alternatively, mechanical engineering graduates can take one or two extra computing classes to learn a bit of computer programming if they intend to have computer companies hire them, which might be a good thing as they would not only have some computer skills but also have some physical knowledge of the systems about which they are programming. Plus there would still be a few computer science faculty left to teach 
the reduced number of computer science classes, and those remaining professors can still carry out research in the area of computer science. Again, the important point for a given student is not what exactly he learns, but rather his struggle to learn technical and general knowledge. College students get a chance to understand their world and it is that struggle to understand, not the specific knowledge they get, which is the value of a university degree. I know many former business and engineering students who had little if any training in computer science and yet they are now full-time computer programmers, which is to say once you understand the structure of science, you can apply it to any discipline.

\section{The University as a Business Subsidy}

The real problem that hinders business is not of hiring students without appropriate expertise. Rather, the real problem that hinders business is hiring and training new students to work at specific tasks, but then having those new workers leave the company after a while to work at other, competitor companies for higher pay. The dilemma, is that the new hiring company does not have to pay to train that worker. Therefore, the business that hired the young worker first, and gave all the training, is left high and dry with all the training costs and yet no worker to get its tasks done. Business is cut throat. So, because worker training costs a lot, businesses want universities to subsidize the training of their workers and to create specialists for their companies which is not exactly what universities are supposed to do according to the idea of a university by Henry. No university can ever teach a student exactly all of the expertise that any given business requires. That does not imply that the University fails businesses; it simply means that business must accept the cost of specific training for their workers so that those workers can carry out their specific tasks. The real problem is that there are few apprenticeship programs where businesses can train and use workers for a long period and where the business is assured of keeping the workers they spend time and money training. However, the lack of worker training is not the purpose of the University since its mandate is to enlighten society.

Since the assumption is that universities are under a budget crisis, then that implies that the University cannot undertake to educate each student to very specific tasks, and the University will have to cut such business subsidies. Nevertheless, having a student who gets an "A" grade in literary writing to write your computer programs can be just as cost effective as having a student who gets an "F" grade in computer programming writing one.

Universities might also complain that if they cut a computer science program, not only will they lose private funding and grants, but that they will lose massive numbers of students, yet many students at a university do not know what they want to be or do. Students do not have the maturity to see the true societal value of education. Indeed, very few students would ever be completely disoriented if there was a missing program. Plus, there are often many student clubs where students can associate and learn new skills such as singing, computing, and business clubs. So there is no reason to believe that a university will lose massive numbers of students just because it cuts one program.

\section{EXAMPLES OF DEEP KNOWLEDGE CUTS}

Consider some program comparisons for cutting at universities, not unlike Gumport (2000). These comparisons are only examples, but they do show interesting analogies of trade-offs between the various programs that universities try to build. It may be unknown which program at a university is the youngest one, which the University will cut, and which program is an old program that that the University will not cut, but they can still be compared with each other to understand each program's value. There is no perfect metric to evaluate the value of one program over another, especially since there can be changing societal fashions.

The concept of deep knowledge is meant to create a more stable society in touch with its deep roots of knowledge, culture and intellectual evolution. The comparisons shown do not imply that universities will be paragons of old style racism, sexism or segregation since university programs and their researchers are professionals in their fields and understand modern sensibilities. Each program that is not cut will still be using cutting edge ideas, still be using the latest knowledge and research in their fields, and still be using all the core courses of a field, and the general ethics courses of modern universities, to impart in each student a high level of education. However, due to budget cuts, there is no known way to determine what fields of study are the most important fields, and so only young programs would be cut, but not young ideas. The knowledge that is still pertinent to every field will always exist. The ideas of equality, justice, and anti-segregation are pertinent to all fields of endeavor and would still have professors researching them within the remaining programs of study and teaching them within the remaining programs. 


\section{Languages}

Consider an example of language program cuts. Two programs may exist, a Chinese Mandarin language program and a French language program. Often, Chinese Mandarin language programs are newer at many universities than are French language programs. Furthermore, there are in the last decade more students entering Chinese Mandarin programs at many universities than who are entering French programs. Nevertheless, the program that would have seniority at many universities would be the French language program since it would, more often than not, be the older program, and, therefore, it would have a deeper academic literature, a deeper connection to the community, and a deeper teaching tradition at most universities. Even though both Chinese Mandarin and French languages are valuable, and even though due to economic circumstances more students may be taking classes in a Chinese Mandarin program compared to a French program, nevertheless the older French program should be kept if it has been at a given university longer.

If a Chinese Mandarin program is cut, then all the students who wish to learn to speak Mandarin can no longer obtain that language skill although they can still take the French program including all the core courses associated with such a program and then learn Chinese elsewhere. They can, for example, find an ethnic Chinese Mandarin speaker who can teach them to speak the language. Or students can go to a specific university or school that still has a Chinese Mandarin program. However, the point of a university degree is not the specific knowledge you gain, but the struggle to understand your world. It is the art of learning a difficult language and the culture, geography and politics of that language that is the most important aspect of studying a language, not the exact language ability itself. Therefore, cutting the newer language program will not cause undue harm to a university or its students.

\section{Economics and Political Science}

If a university needs to cut more, it might be forced to cut an economics program or a political science program. In many universities, it is the political science program that is older than the economics program, and so the University would be forced to cut the economics program before political science. Some might argue that you cannot cut economics because it is the grounding foundation of our modern economic way of life and the basis for business, which in turn creates economic growth and our high standard of living, as Gorman, Hanlon, and King (1997) explain. Political science, though, has, in many universities, a deeper, longer tradition of academic work than does economics. So, if political science is the older program, then you would cut the economics program before you would cut the political science program. Indeed, economics is derivative of political science as economics used to be called political economy when it was in its early manifestation within most political science programs. Therefore, most universities when comparing the two programs will be forced to cut economics before they would cut political science.

If a society needs more economists, those economists can be trained at specialty schools, or trained at big banks, or trained at businesses, or trained at economic institutions. Employers who need specific economists will be forced to underwrite the students own economics training if the employers need to have well-trained economists. If there is a need for an economist, an institution can just hire a political science major and have him read up on economics as many a Nobel Laureate in economics has done. Such a student will be just as good as any economist for any given advisory role on economics. In reality economists, such as a Federal Reserve chair or a bank president or an advisor to business, are often confronted with political expediency when they decide delicate economic issues with which huge gains and losses to people occur. Because of the intense politics surrounding economic issues, it can be said that economics and the economics profession tend to decide things more in regard to politics than in regard to economics. Nevertheless, if a university cuts an economics program, it is still possible to have economic professors teach in the political science department, or to have political economy classes with an emphasis in economics within the new political science department.

Indeed, if a university cuts an economics program, some of its faculty may, due to seniority, move over to the political science department. Then the two departments will have to decide together how courses are set up and how it shall cut faculty further within the department and considering the needs of senior faculty. Nevertheless, the new slightly bloated political science department and those remaining economics professors can carry on important economic research. And they can carry on teaching some economics courses as there may remain some economics courses taught within the political science curriculum. 
Many will argue that without economics, you cannot have business and business schools and business majors. However, often economics programs are older than business programs; so long before you will have to cut economics, you will have to cut business programs themselves. Then the uproar will be about cutting business programs where students need learn to conduct business. Much of what business is and does is about what is economically or politically expedient. Business people spend much of their time dealing with people, not dollars. Furthermore, many of histories' top businessmen, Henry Ford, John D. Rockefeller, and Andrew Carnegie had little or no business training. They did hire top business people with lots of business training, but what a business needs to do to be successful is to hire a political science major and have him take a few business classes to understand business tactics. The new business hire will simply have to learn a few new skills, just like many business majors have to do when their training lacks certain business skills such as how to deal with managing people. There is no such thing as perfect expertise in business. Therefore, political science majors may have a better background for carrying out successful business transactions than many business majors.

\section{Philosophy and Political Science}

If further cuts are needed, it may be necessary to choose between cutting philosophy or cutting political science. In many universities, the philosophy program is older than the political science program and so according to the deep knowledge ideal, a university would be forced to cut political science before it cuts a philosophy program. However, businesses can just as easily hire philosophy majors as it can hire business, economics or political science majors to run their businesses. In the end, doing business is a philosophical endeavor as much as it is a purely economic and profit oriented endeavor. After all, since the financial crisis erupted in 2008, and even before that, much of society has been quite dissatisfied with the profit motive, with CEO pay incentives, and with leveraged buyouts. People often believe that a lack of ethics (one particular field of philosophy) is the cause. The emphasis on ethics means that business should hire philosophy majors in the first place since they can learn business concepts on the fly. Plus, due to the importance of having both arts and sciences in core courses, such a philosophy major should have good math and science skills to be able to learn business concepts. Moreover, philosophy majors will understand the deeper meaning of business, which is to provide society with its needs and to have society decide what those needs are. They will have a well-rounded background for helping the customer.

\section{Biology and English Literature}

Another example of a possible program cut at a university is where the University cuts a science program like biology rather than a humanities program like English literature where either one or the other has to be cut. Most would say that you cannot possibly cut biology because that is how we will have new investment in new drugs and new medical technologies that will not only help economic growth and prosperity but also help people's health and the health of the planet. Furthermore, biology is central to understanding environmental degradation. In many universities, English literature programs might be the older program compared to biology, and so the University would cut biology before English literature.

You could argue, though, that many biology majors do not need all of the biology classes they have to take within their major to do their jobs, such as in nursing, in medicine, and for drug testing. Indeed, drug testing has a lot to do with politics as well as biology and so what a biologically based company can do is hire a literature major and teach him how to run experiments and a few biological processes that he needs to understand. Or students can go to a specialist biology program if they need to work extensively in a biologically based field after their first literary degree. Many may think that this is a strange idea using English majors to run biology processes, but again it is the struggle to learn and not what is learned that makes a university useful. If a university experience is only as valuable as what is learned, then that means all biology students would have to spend half of every day after college reading up on the latest biological breakthroughs around the world to be competent biologists. After all, the field of biology is extremely wide and changes quite rapidly. Since it is not the case that newly graduated biology majors can keep up with all the latest biology information, then most people working in biology only know a little bit about all of the enormous biological knowledge out there. Working in a biology based profession, then, requires many practical skills that a college can never hope to cover. 
If you cannot hope to know absolutely everything about biology to be a biologist or a professional in a biological based profession, then it is possible to become an English major and get the proper training for biology later. A professional can learn later what $\mathrm{x}$ and $\mathrm{y}$ chromosomes are or what biological diversity is, or how to give a shot, or how to mix some drugs, or how to fill a beaker. Probably few biology based workers have to know such details. For example, nursing is a profession that more often than not deals with the interaction of people than with the understanding of a person's exact biology. Therefore, maybe nurses would interact with patients better by having more English literature as opposed to having more biology. Indeed, there is often much concern that biologists and technologists who use biology have lost their ethical foundation which suggests that having those people study more English literature is appropriate.

Also, just because a university cuts a biology program, does not mean that there would not be some biology classes included in most curriculums since arts and sciences would include some biology classes. Those professors who remain that can teach biology can also continue to conduct biological research and could continue to obtain grants for major research projects. The University can house those remaining biology professors in the sciences. You may even want to add a few classes of biology that some literature students would like such as how biology has affected history.

Therefore, knowing biology well is not always what is necessary. Rather, what is necessary is having the ability to think critically about biological concepts. What makes a good biologist is one who knows how to struggle with new challenges and new processes and new knowledge which a literature degree is just as capable of providing as a biology degree. There is too much trust in technology and knowledge as an end in itself and not enough trust in the process of attaining technology and knowledge. Of course, an English literature student can go on to obtain a masters degree in biology and take some of those masters' prerequisites during undergraduate work, or students can go to a university that does have a biology specialty. Classes in a literature major may provide insight into biology that a senior biologist would find helpful.

\section{Religion and Physics}

Consider physics and religion. If a religious program is older than a physics program, then the University would be forced to cut physics, which is the basis of most science and technological work, as McAdam and Welsh (2000) show, and keep a religion program. Such a cut may seem irrational. Still, it is possible to have mathematics, physics and chemistry as foundation courses for religion majors, it is just that the University would cut the physics major itself. Indeed, a religious major, with some basic math and science foundation courses, can still work in an advanced technological economy. It is the struggle to understand the world along with the basics of arts and sciences that will help a student to be successful in technological fields rather than the specific knowledge itself. Having a religious degree with some basic science courses can free one from the shackles of "the way it's always been done," and to experiment more fully with new technologies. Plus, there is still the possibility of getting a graduate degree in the sciences or taking technically appropriate classes elsewhere or having firm-specific training for new employees with specific sciences that pertain to what is needed. So cutting physics and keeping religion does not matter as much as you would expect.

Some might fear that there is a danger that if the University keeps religion over physics, then that implies society will become more racist, sexist or bias. However, there are as many religious ethics classes taught as there are physics ethics classes taught. After all, many times it has been the case that society has questioned new technology, such as computers, regarding their ethical use and their effect on society. Having students who know religion could make such technologically cutting edge businesses better at understanding the ethics of inventing and using technology. Religion has a deep knowledge base and that knowledge base has dealt with many of the challenges of human history just as the deep physics knowledge base has done. And that deep religious knowledge base implies an understanding of physics itself.

\section{THE RESEARCH MODEL UNDER DEEP KNOWLEDGE}

According to Aesop, there was a race between a tortoise and a hare. The tortoise made slow, steady progress while the hare went fast for a while then took rest breaks and ate food. You would have expected the hare to win the race, but because the hare was foolish and did not stick to his purpose, he lost the race to the tortoise. 
This story might also be an interesting example of much of our scientific research, as DeBoer (1991) explains. Sometimes we are so enamored with technological progress that we forget purpose and goals. For example, we have now many advances in construction science and materials, which might suggest that we have the means to build any type of building anywhere in the world, and to build it at a low-cost. However, there was once a new house designed and built for use in the far north, arctic climate, where there is server cold, snow, and permafrost. When some people saw the new advanced, high-tech house, it seemed to them that the house looked awfully similar to the old traditional housing of the peoples of the Northern Arctic. The story suggests that traditional knowledge can be just as important in conducting research as high-tech, new knowledge can be. Therefore, it is just as important to keep senior university programs with a good research agenda going as much as it is to have new, young research programs. The example does not mean there will not be research in new lines of knowledge, just that researchers can take advantage of and regard highly an old line of knowledge.

Sometimes going fast into new lines of knowledge and new lines of research can waste time, just as much as going too slow and reemphasizing old lines of knowledge can waste time. Normally, though both old and new lines of knowledge are helpful in research, and old programs can also have new lines of research. Certainly a physics program if kept can include a computer science professor working in new lines of research in computers even though the University may cut the computer program itself. A literature program can include a political scientist or an economist to bring out some aspect of literature that deal with politics or economics. A political scientist or economist in a literature department that teaches about Adam Smith can do research in cutting-edge political science or economics. But the emphasis of the overall program is still on literature. Such cuts with the addition of other professors from other fields can blur the lines of what a program means. It is still up to each department and their faculty to determine the emphasis and needs of that department. That suggests that the politics within a given department can be quite brutal as one department is forced to take professors from another department. Nevertheless, democracy should hold sway and discussions should be civil.

However, when considering what makes certain knowledge and certain subjects important for a university to pursue, it is still possible to pursue the latest knowledge within a given field. The University does not necessarily need to pursue the latest research in science, art or business, but it can still research the latest knowledge and information about the given fields of science or art that remain. Interestingly, the idea of going back to deep roots is already done by some universities such as St. John's College in Santa Fe, New Mexico, U.S.A. where students read philosophy, literature and science books from the earliest human history to the latest in sequence.

Nevertheless, even though universities do much important research, they do not carry out all of the world's research as industry, government agencies and other institutions do research as well. And there is always more research that is needed. However, if a university must cut programs because of budgetary concerns, then there is no way to put a value on which research is more or less able to help society than any other research. A university can only help so much. If a university needs to cut programs, then keeping the deeper knowledge can be as valuable as listening to elders or reading and studying ancient history. Even biologists can sometimes glean important information from elders about biological systems.

\section{VITAL PROGRAMS FOR A LOCAL REGION}

Many universities have important regional-centric schools such as in education, medicine and law that the University's regional communities depend on for professionals in that field. Also, the region may depend on important research in those fields covered by the local university which is made relevant to the regional needs. Plus, distance delivery of programs is often a difficult prospect as Borba and Villarreal (2005) explain. What can happen, is that many programs that are new, young programs to a university may be important for a community, and so it might be suggested that those programs should be allowed to stay based on the criteria of local needs. Nevertheless, even when there are such programs vital to regional needs, if a community cannot pay for all of its programs, then those programs need to be cut if they are junior programs. There will be other universities with those specific programs around the country which are old, well-established programs in those fields, and which can take care of any given region's educational and research needs, even if they are in faraway cities. Furthermore, other countries will also have universities with those programs as well. Students can then do their studies where universities offer the courses, and professors in faraway lands can do regional specific research. Considering available substitutions, there is no such thing as a vital program 
for a given region, and the needs of any specific region will be taken care of by one or another university outside of that region.

When considering the need for regional specific accreditation of a professional, if there is a problem with professionals obtaining proper accreditation when graduating from a different region's university, then the outside university can simply set up an accredited test or a set of classes to take care of the need. Clearly, you cannot have every single profession's accreditation needs taken care of by a university in a sparsely populated region. You cannot have a professional engineer's qualifications for every engineering field. You cannot have an educator's qualifications for every educational subject. You cannot have a veterinarian qualification for every animal type. You cannot have a medical specialist qualification for every medical specialty. Therefore, many regions have to depend on other regions' universities for their professional qualification needs. If accreditation is different from one region to another, due to specific needs of a region, then a special test or special classes can be set up by the sparsely populated regions accreditation body for that specific need. Such tests and classes can even be set up at appropriate universities in other regions if needed. Such specialty needs do not require an entire university program in a sparsely populated region just to take care of the need.

Indeed, many regions have cross-boundary agreements for taking in students from one region to another for the express purpose of educating specific professionals for needs of the other region. Such agreements can allow students from any region to get the specific professional qualifications they need for their small sparsely populated region.

\section{Specific Regional Research Needs}

Sometimes it is important to have a specific research agenda in a specific professional field that is important to a specific region, such as researching a specific type of disease, cultural trend or set of laws that are important to a region. Having a program in such areas, locally, allows new research to help develop and understand those regional specific subjects.

However just because a program does not exist in a local region where that particular field is important, does not mean regional specific research will never occur. There is much research done in other, outside regions by non-local university professors and programs. To say that the only way anyone can do regionally specific research is if there are universities and university programs geographically located where the research need occurs is to assume researchers are incapable of understanding other times or other places or that they cannot travel to a location for a more intimate understanding. It may be true that if a professor is not from a region and yet does research in that region, he or she does not understand completely all the intricacies and characteristics that make the researched region so unique. Nevertheless, if every researcher were required to live at a time or in a place that they were researching in order to truly understand that time or place, then researchers would not undertake much important research. For example, how would researchers study such things as history, or virus evolution in remote locations, or weather patterns in the middle of the ocean if they could not study such subjects remotely.

Research is never perfect. Money is never endless. The only thing a given university can do given the limitations of money and the extensive demands of a region's educational, service, and research needs is to choose appropriate programs to keep and to cut. Since the evolution of a given university suggests that the University initiated its most important programs first in its history, and the University initiated less important programs later in its history, then cutting in reverse order makes sense. Some may suggest that a region changes over time and, therefore, that region's priorities, needs and cultural milieu evolve and, therefore, the University programs to be cut need to be evaluated regarding the latest regional history. However, it can be just as important for a region not to forget its deepest roots as an institution of research. Plus, the programs that the University keeps can still use and research ideas from the cut programs such that not every important aspect of a cut program will be lost.

Many researchers cannot possibly live in or be near times, locations or social milieus about which they must do research, and yet such research is important. Therefore, when a university cuts a program, it does not mean that no one will undertake important regional specific research. If there is a need, many researchers in many regions will find out about that need and will research it. So the idea that the only way to have pertinent local research for specific regions is by having local researchers is not true. 
Furthermore, when a region institutes a new university or college from nothing, that university may start out with a wide variety of programs some of which may need to be cut for budgetary purposes. In those cases, where there are equally senior programs, but the University must cut one program and keep one program, the program with the longest tradition at other universities in that region or nearby regions should be kept.

\section{CONCLUSION}

There is no perfect way to make cuts at a university when funds and budgets are limited as Mills (2007) explains. Cutting university faculty pay is not a good option as it makes it difficult to attract the best professors and such pay cuts cause faculty to have to teach extra classes, or work extra jobs to make ends meet which reduces the effectiveness of a vibrant research agenda. Cutting programs along a business model may be more a case of fashion rather than substance. Usually such cuts using a business model look at student numbers to determine vibrant and non-vibrant programs. It is interesting, though, that society would actually decide to base its important university research model on the whims of young students, who do not yet have a lot of life experiences.

The deep knowledge criteria of cutting may be the lesser of evils for university cuts. Deep knowledge means cutting the most junior programs first and cutting senior programs last in reverse order of the progression of a university's evolution. The University keeps the oldest programs and it terminates the youngest programs, which is a more practical method of cutting a university along the lines of seniority of knowledge. Deep knowledge implies that an old program within a university has a deeper knowledge base, a more extensive academic literature and greater interactions with the surrounding community than any other discipline, even though those connections are not always obvious. As such, it can be argued that senior programs give a university its greatest value. It does not necessarily mean cutting all faculty within a program during a program reduction, as seniority and the ability of faculty to be relocated in other departments will play a role. Nevertheless, if cuts are needed, this is one way to do it.

Therefore, first cut the most junior programs or majors. If a university institutes programs simultaneously, then it needs to use regional academic history to determine junior or senior status for a program. Next, move senior faculty based on employment rules, such as not cutting full professors, to other programs. Then other programs can choose to retain some of the cut classes.

There are in the economy many employees who took university classes in an age where they had few if any computing classes, few Excel classes, few Word typing classes, or few Power Point classes, and yet they can use those technologies effortlessly. Thus, it is possible to have had no specific learning in these technologies and yet be able to learn how to use them within days. What students need to know, though, is how to write well, how to make reports, how to talk in front of people and how to conduct a philosophical, mathematical and scientific inquiry. With such skills, most students within a few days or hours can learn to write reports with Word, give presentations with Power Point, and run programs and spreadsheets without having had specific classes for those technologies.

John Henry's The Idea of a University should be taken more seriously in academic governance. Each university should not emphasize the understanding of the latest knowledge but emphasize the development of each student's mind. Developing students include developing their writing skills, logic skills, and cognitive thinking skills not to mention developing within each student a broad knowledge base in all subject matters. Moreover, most college students in any major must take basic literary arts, science and computer classes that teach basic skills, which allow those students the capacity to learn how to use spreadsheets, word processors, and presentation technologies. Plus, just because a university cuts a "high-tech" academic program does not mean a class or two cannot remain from the program, from which a leading professor can continue to conduct research in the field.

There is nothing easy about cutting a university. There are no perfect solutions, only a messy, difficult process. In the end, John Henry said it best when he said,

The view taken of a University in these Discourses is the following: - That it is a place of teaching universal knowledge. This implies that its object is, on the one hand, intellectual, not moral; and, on the other, that it is the diffusion and extension of knowledge rather than the advancement. If its object were scientific and philosophical discovery, I do not see why a University should have students; if religious training, I do not see how it can be the seat of literature and science. 
Henry might also add, if the University is only meant to create workers, then just subsidize every new young worker for four years so that they can learn the specific skill of their employer. As someone once said, information technology is not the "thing," it is only the thing that lets you find the "thing," i.e. the thing you are truly looking for is not the technology itself, but rather the humanities. However, finding the "thing" you are looking for requires a broad knowledge base.

\section{AUTHOR BIOGRAPHY}

Dr. Douglas B. Reynolds studied energy economics at the University of New Mexico and received his Ph.D. in 1994. He taught economics from 1995 to 1997 at Kazakstan's Institute of Management, Economics and Strategic Research (KIMEP), in Almaty, the Republic of Kazakstan in the former Soviet Union. He is now a Professor of Economics at the University of Alaska Fairbanks, where he has been since 1997. He has lived, given lectures, and researched in Norway, Russia, Mexico, Poland, France and Turkey. Dr. Reynolds has published many books, journal articles, and reports and is the grievance chair for his academic Union.

\section{REFERENCES}

Armstrong, Michael J. (2003). "Students as Clients: A Professional Services Model for Business Education," Academy Of Management Learning And Education, December 1, volume 2, number 4, pp.371-374.

Borba, Marcelo C. and Monica E. Villarreal, (2005). Humans-with-Media and the Reorganization of Mathematical Thinking: Information and Communication Technologies, Modeling, Experimentation and Visualization, Springer, New York.

Carlsona, Peter M. \& Mark S. Fleisherb (2007). “Shifting Realities In Higher Education: Today's Business Model Threatens Our Academic Excellence," International Journal of Public Administration, Volume 25, Issue 9-10, pages 1097-1111.

DeBoer, George E. (1991). A History of Ideas in Science Education: Implications for Practice, Teachers College Press, New York.

Gorman, Gary, Dennis Hanlon, and Wayne King. (1997). "Some Research Perspectives on Entrepreneurship Education, Enterprise Education and Education for Small Business Management: A Ten-Year Literature Review," International Small Business Journal, April 1997 volume 15, number 3, pp. 56-77.

Gumport, Patricia J. (2000). "Academic restructuring: Organizational change and institutional imperatives, Higher Education number 39: pp. 67-91.

Jackson, Matthew O. (2014). "Networks in the Understanding of Economic Behaviors," Journal of Economic Perspectives, Volume 28, Number 4, Fall 2014, pp. 3-22.

McAdam, Rodney and William Welsh, (2000) "A critical review of the business excellence quality model applied to further education colleges", Quality Assurance in Education, Volume 8, Issue 3, pp.120 - 130.

Mills, Michael R. (2007). "Stories of Politics and Policy: Florida's Higher Education Governance Reorganization," The Journal of Higher Education, Volume 78, number 2, pp. 162-187.

Mitchell, Donald W. and Carol Bruckner Coles, (2004) "Establishing a continuing business model innovation process," Journal of Business Strategy, Volume 25 Issue 3, pp. $39-49$.

Newman, John Henry Cardinal (1852). The idea of a University, Catholic University, England.

Sullivan, Jerome M. (2004). Academic Restructuring: Identification of Criteria Rated for Importance and Used to Establish, Merge, Or Eliminate a College Or School Within Selected State Supported Institutions of Higher Education, University of Toledo. 